International Journal of Maternal and Child Health and AIDS (202I), Volume I0, Issue 2, 22I-230

\begin{tabular}{ll}
\hline & INTERNATIONAL JOURNAL of \\
& MATERNAL and CHILD HEALTH and AIDS \\
& ISSN 216I-864X (Online) \\
& ISSN 216I-8674 (Print) \\
& DOI: 10.21 I06/ijma.525 \\
\hline
\end{tabular}

ORIGINALARTICLE | HIVTESTING

\title{
Determinants of HIV Testing Uptake among Women (aged I5-49 years) in the Philippines, Myanmar, and Cambodia
}

\author{
Wah W. Myint, $M S^{1}$; David J.Washburn, $\mathrm{ScD}^{2}$; Brian Colwell, $\mathrm{PhD}^{\prime}$; Jay E. Maddock, $\mathrm{PhD}^{3}$ \\ 'Department of Health Promotion \& Community Health Sciences, Texas A\&M University School of Public Health, College Station, TX, USA; ${ }^{2}$ Department \\ of Health Policy \& Management, Texas A\&M University School of Public Health, College Station, TX, USA; ${ }^{3}$ Department of Environmental \& Occupational \\ Health, Texas A\&M University School of Public Health, College Station, TX, USA \\ \Corresponding author email:wah@tamu.edu
}

\section{ABSTRACT}

Background: Many countries have been trying to eliminate Mother-to-Child transmission of the Human Immunodeficiency Virus (HIV) and achieve the $90-90-90$ target goals. The targets mean that $90 \%$ of People Living with HIV (PLWHIV) know their HIV status, $90 \%$ of those who are infected receive Antiretroviral treatment (ART), and $90 \%$ of those achieve viral suppression. Despite some progress, the goals have not been met in the Philippines, Myanmar, and Cambodia, countries with relatively high or growing HIV prevalence. This study identifies the sociodemographic determinants of testing among women in these countries so that better health education and stigma reduction strategies can be developed.

Methods: Descriptive and multivariable analyses were conducted using Demographic and Health Survey data conducted in the Philippines (20I7), Myanmar (20I5/20I6), and Cambodia (20I4). The outcome variable was having ever been tested for HIV. Independent variables included knowledge and attitudes about HIV and social determinants of health.

Results:A significant difference in testing rates among women was observed (the Philippines: $5 \%$, Myanmar: 19\%, Cambodia: 42\%). In Myanmar and Cambodia, women who had more HIV knowledge and less stigma towards PLWHIV were more likely to get tested for HIV than those who did not. Marital status, education, wealth were strong predictors for HIV testing among women. Younger women aged I5-19 and those who live in the rural areas were less likely to get HIV tested than older and those living in urban areas. Employed women were less likely to seek an HIV test than the unemployed in Myanmar and Cambodia, whereas, in the Philippines, the opposite relationship was found.

Conclusion and Global Health Implications:Women with less education and those less familiar with HIV should be targeted for HIV testing interventions. Stigma reduction and different testing strategies could facilitate early screening leading to improved HIV testing among women.

Keywords: • HIVIAIDS • HIV Testing • Women • HIV Prevention • Stigma and Discrimination • Southeast Asia 


\section{Introduction}

\section{I. Background of the Study}

The Asia and the Pacific region had the secondhighest prevalence of Human Immunodeficiency Virus (HIV) globally, with 5.8 million people living with HIV (PLWHIV) in 2020.' For many years, countries in Southeast Asia (SEA) have been trying to eliminate Mother-to-Child Transmission (EMTCT) of HIV. In 20I4, the World Health Organization (WHO) set three criteria for achieving EMTCT. ${ }^{2}$ These criteria were related to three impact indicators, which need to be met for at least one year and three process indicators, which need to be met for at least two years to successfully achieve EMTCT. ${ }^{2}$ In 2016, UNAIDS and its partners committed to achieve three $90 \%$ targets by $2020.90 \%$ targets mean $90 \%$ of PLWHIV know their HIV status, $90 \%$ of those who know their HIV status received Antiretroviral treatment (ART), and $90 \%$ of those who received ART will have viral suppression. ${ }^{3,4}$ Viral suppression is achieved when one has HIV amount less than 200 copies of the virus per milliliter of blood and preventing HIV transmission to others. ${ }^{5} \mathrm{HIV}$ is 26 times more contagious during the early stage, that is the first three months after virus acquisition than later. ${ }^{6}$ Knowing one's HIV status allows people to begin ART sooner, leading to achieving viral suppression and further reducing the risk of HIV transmission to others. ${ }^{4,5,7}$ Therefore, early testing in women is important to achieve EMTCT and $90 \%$ targets. ${ }^{7}$

Thailand is the first country in SEA to achieve EMTCT. Although Thailand's adult HIV prevalence was $1 \%$, the highest HIV prevalence in SEA, it had already achieved $90 \%$ targets by 2020 . $^{1,8}$ Myanmar, being second highest, has an adult HIV prevalence at $0.57 \%$ in 2016 , whereas Cambodia, being thirdhighest, had an adult HIV prevalence at $0.5 \%$ in 2020. 1,9 Estimated adult HIV prevalence in the Philippines was $0.2 \%$; however, it showed a rapid rise, the highest in HIV new infections in SEA: a $240 \%$ increase from 2010 to $2020 .{ }^{10}$ The estimated percentage of testing among adult women was $65 \%$ in the Philippines and $82 \%$ in Cambodia in 2020. ${ }^{1,11}$ Myanmar data on HIV testing among adult women were not available.'
Recent studies in Cambodia and Myanmar focused on people who use drugs and pregnant women, whereas work in the Philippines examined the influence of age and wealth on HIV testing. ${ }^{12-14}$ Studies in South Africa and Central Asia focused on the association between HIV-related knowledge and stigma and HIV testing. ${ }^{15,16}$ However, in the Philippines, Myanmar and Cambodia, there was limited literature regarding the influence of HIV-related knowledge and stigma, and sociodemographic factors on HIV testing uptake among women, which are critical to achieve the global goals., 17

\section{I.2. Objectives/Specific Aims}

Due to the relatively higher rates in Myanmar and Cambodia, and the rapid rise in HIV prevalence in the Philippines, as well as the work that remains to be done to achieve the $90 \%$ targets, this study helps to identify the determinants of HIV testing among women in these three countries. The findings from this analysis will help to better target interventions aiming at increasing testing rates for women.

\section{Methods}

For this study, we used secondary data from the Philippines National Demographic and Health Survey (PDHS 2017), Myanmar Demographic and Health Survey (MDHS-20I5/20I6), and Cambodia Demographic and Health Survey (CDHS-20I5). ${ }^{18-20}$ A total of 55,537 women respondents from three countries (Philippines: 25,074; Myanmar:I2,885; Cambodia: 17,578) participated in the surveys. ${ }^{18-20}$ The surveys were large, cross-sectional, and nationally representative, which used multi-staged random sampling. ${ }^{21}$

\section{I. Study Variables}

The outcome variable used was whether or not a respondent had been tested for HIV with a dichotomous response (yes/no). The main independent variables used were HIV knowledge scores and stigma. The HIV knowledge score was a summation of the correct scores on six knowledge questions (HIV is transmitted during pregnancy, HIV is transmitted during delivery, HIV is transmitted during breastfeeding, one can get HIV from mosquito bites, one can get HIV by sharing food, a healthy- 
looking person can have HIV). One point was assigned for each correct answer, and the total score ranged from zero to six. The stigma-related variable was a single item asked across all three countries: willingness to buy vegetables from a person living with HIV. Although four other stigma-related questions were asked in the PDHS (2017), those questions were not asked in CDHS (20I4) or MDHS (20I5), where different stigma-related questions were asked. ${ }^{18-20}$ For comparability purposes, we did not include those questions in our analysis.

\subsection{Covariates}

The covariates used were 5 -year age groups (1519, 20-24, 25-29, 30-34, 35-39, 40-44, 45-49), place of residence (urban, rural), education (primary education and less, secondary education, higher education), and wealth status (poor, middle, rich). Wealth, a composite variable created by DHS, was calculated based on the household's ownership of televisions, bicycles, types of access to water and sanitation facilities, and materials used for the construction of the house. ${ }^{22}$ We also used marital status (never married vs. ever married) and employment status (currently working or not).

\subsection{Statistical Analysis}

All estimates were weighted using "svy" commands in Stata 16.0. ${ }^{23}$ First, we performed descriptive analysis to observe weighted frequency and percentage. Second, since the independent variables were dummy or categorical variables (except the knowledge score), we used the Pearson-Chi2 test to observe associations between the outcome and independent variables. Third, we performed independent samples t-tests assuming unequal variance to observe the differences in HIV knowledge score between the women who were ever tested for HIV and those who did not. Finally, we conducted multivariable logistic regression to predict the likelihood of HIV testing uptake among women.

\subsection{Ethical Approval}

This study used unidentifiable secondary data, which are publicly available upon request to the DHS program. The protocol for DHS surveys was reviewed and approved by the Inner City Fund (ICF) Institutional
Review Board (IRB) for all three countries and respective country's Ministry of Health or Executive and Technical committee (for the Philippines and Cambodia) or Ethics Review Committee (for Myanmar). ${ }^{15-18}$ Also, informed consent was obtained from each participant before the interviews. ${ }^{15-18}$

\section{Results}

\section{I. Sociodemographic Characteristics}

The results of descriptive, bivariate, and multivariable analyses are described below. The bivariate analyses showed statistically significant associations between the outcome variable and independent variables (Table I). Our multivariable regression showed different patterns in three countries (Table 2).

\section{I.I.Age groups}

The highest percentage of respondents was from I519 years (about 20\%) in the Philippines. In Myanmar and Cambodia, the respondents from age 30-34 groups were the highest (16\% and $17 \%$, respectively). In all three countries, women aged 25-29 were significantly more likely to be tested for HIV than the women aged 15-19, and the highest odds ratio was observed in the Philippines (aOR=3.94, 95\% Cl: 2.12-7.33).

\section{I.2. Place of residence (urban/rural)}

$19 \%$ of respondents in Cambodia, $29 \%$ of respondents in Myanmar, and 49\% in the Philippines lived in urban areas. Respondents from rural areas were significantly less likely to get tested for HIV, and the lowest odds ratio was seen in the Philippines (adjusted odds ratio $(\mathrm{aOR})=0.42,95 \% \mathrm{Cl}: 0.29-0.6 \mathrm{I})$.

\section{I.3. Education}

A greater percentage of respondents (36\%) had higher education in the Philippines compared to those from Myanmar (I0\%) and Cambodia (5\%). In all three countries, women with higher levels of education were more likely to get tested for HIV compared to those without any education, and the highest odds ratio was seen in Myanmar (aOR=2.67, 95\% Cl: 2.08-3.43).

\section{I.4. Wealth}

Wealthier women were more likely to get tested for HIV than poorer women, and the highest odds ratio 
Table I: Bivariate analysis of the association between the having been tested for HIV and sociodemographic characteristics

\begin{tabular}{|c|c|c|c|c|c|c|}
\hline Country \& survey year & \multicolumn{2}{|c|}{ Philippines (2017) } & \multicolumn{2}{|c|}{ Myanmar (2015-2016) } & \multicolumn{2}{|c|}{ Cambodia (2014) } \\
\hline Original number of observations & \multicolumn{2}{|c|}{$N=25,074$} & \multicolumn{2}{|c|}{$N=12,885$} & \multicolumn{2}{|c|}{$N=17,578$} \\
\hline Variables & No: N (\%) & Yes: N (\%) & No: N (\%) & Yes: N (\%) & No: N (\%) & Yes: N (\%) \\
\hline Age & \multicolumn{2}{|c|}{$\mathrm{p}<0.001$} & \multicolumn{2}{|c|}{$p<0.001$} & \multicolumn{2}{|c|}{$\mathrm{p}<0.001$} \\
\hline Overall & $24,275(97 \%)$ & $799(3 \%)$ & $10,130(79 \%)$ & $2,753(21 \%)$ & $10,165(58 \%)$ & 7, $394(42 \%)$ \\
\hline $15-19$ & $5,088(99 \%)$ & $32(1 \%)$ & $\mathrm{I}, 753(96 \%)$ & 81 (4\%) & $2,585(86 \%)$ & $420(14 \%)$ \\
\hline $20-24$ & $3,772(96 \%)$ & $142(4 \%)$ & I, $513(80 \%)$ & $380(20 \%)$ & $\mathrm{I}, 5 \mathrm{I} 2(50 \%)$ & $\mathrm{I}, 525(50 \%)$ \\
\hline $25-29$ & $3,503(95 \%)$ & $183(5 \%)$ & I, 301 (69\%) & $578(31 \%)$ & $\mathrm{I}, 02 \mathrm{I}(36 \%)$ & I, $837(64 \%)$ \\
\hline $30-34$ & $3,122(95 \%)$ & $165(5 \%)$ & I, $362(69 \%)$ & $609(31 \%)$ & $1,212(41 \%)$ & I, $778(59 \%)$ \\
\hline $35-39$ & 3, $172(96 \%)$ & $119(4 \%)$ & I,389 (72\%) & $529(28 \%)$ & $\mathrm{I}, 005$ (57\%) & $771(43 \%)$ \\
\hline $40-44$ & $2,814(97 \%)$ & $89(3 \%)$ & I, 373 (79\%) & $373(21 \%)$ & $1,348(68 \%)$ & $645(32 \%)$ \\
\hline $45-49$ & $2,804(98 \%)$ & $69(2 \%)$ & I, 439 (88\%) & $203(12 \%)$ & $\mathrm{I}, 482(78 \%)$ & $418(22 \%)$ \\
\hline Place of residence & \multicolumn{2}{|c|}{$\mathrm{p}<0.00 \mathrm{I}$} & \multicolumn{2}{|c|}{$\mathrm{p}<0.00 \mathrm{I}$} & \multicolumn{2}{|c|}{$p<0.001$} \\
\hline Overall & $24,275(97 \%)$ & 799 (3\%) & $10,130(79 \%)$ & $2,753(21 \%)$ & $10,165(58 \%)$ & $7,394(42 \%)$ \\
\hline Urban & $8,514(94 \%)$ & $502(6 \%)$ & $2,589(68 \%)$ & I, $196(32 \%)$ & $2,778(49 \%)$ & $2,885(51 \%)$ \\
\hline Rural & $15,76 \mid(98 \%)$ & $297(2 \%)$ & $7,54 I(83 \%)$ & I, 557 (I7\%) & 7,387 (62\%) & $4,509(38 \%)$ \\
\hline Education & \multicolumn{2}{|c|}{$p<0.001$} & \multicolumn{2}{|c|}{$p<0.001$} & \multicolumn{2}{|c|}{$p<0.001$} \\
\hline Overall & $24,275(97 \%)$ & $799(3 \%)$ & $10,130(79 \%)$ & $2,753(21 \%)$ & $6,606(47 \%)$ & $7,394(53 \%)$ \\
\hline No education/Primary education & 4,121 (99\%) & $46(1 \%)$ & $5,650(84 \%)$ & $1,069(16 \%)$ & $6,115(61 \%)$ & $3,929(39 \%)$ \\
\hline Secondary & $12,130(98 \%)$ & $289(2 \%)$ & $3,685(76 \%)$ & I, $153(24 \%)$ & $3,559(55 \%)$ & $2,972(45 \%)$ \\
\hline Higher & $8,024(95 \%)]$ & 464 (5\%) & $793(60 \%)$ & $531(40 \%)$ & 491 (50\%) & $493(50 \%)$ \\
\hline Wealth & \multicolumn{2}{|c|}{$p<0.00 I$} & \multicolumn{2}{|c|}{$\mathrm{p}<0.00 \mathrm{I}$} & \multicolumn{2}{|c|}{$p<0.001$} \\
\hline Overall & $24,275(97 \%)$ & 799 (3\%) & $10,130(79 \%)$ & $2,753(21 \%)$ & $10,164(58 \%)$ & 7, 394 (42\%) \\
\hline Poor & $11,256(99 \%)$ & $166(1 \%)$ & $4123(86 \%)$ & $690(14 \%)$ & $4,099(67 \%)$ & I, $998(33 \%)$ \\
\hline Middle & $4,683(96 \%)$ & $173(4 \%)$ & 2 I5। (82\%) & $482(18 \%)$ & I, $682(60 \%)$ & I, I I0 (40\%) \\
\hline Rich & $8,336(95 \%)$ & $460(5 \%)$ & $3856(71 \%)$ & I $58 \mid(29 \%)$ & $4,383(51 \%)$ & $4,286(49 \%)$ \\
\hline Marital status & \multicolumn{2}{|c|}{$\mathrm{p}<0.00 \mathrm{I}$} & \multicolumn{2}{|c|}{$\mathrm{p}<0.00 \mathrm{I}$} & \multicolumn{2}{|c|}{$p<0.001$} \\
\hline Overall & $24,275(97 \%)$ & 799 (3\%) & $10,130(79 \%)$ & $2,753(21 \%)$ & $10,165(58 \%)$ & $7,394(42 \%)$ \\
\hline Never in union & $8,473(98 \%)$ & $179(2 \%)$ & $3827(92 \%)$ & $319(8 \%)$ & $4092(88 \%)$ & $559(12 \%)$ \\
\hline Ever in union & $15,802(96 \%)$ & $620(4 \%)$ & $6,303(72 \%)$ & $2,434(28 \%)$ & $6,073(47 \%)$ & $6,835(53 \%)$ \\
\hline Current employment Status & \multicolumn{2}{|c|}{$p<0.001$} & \multicolumn{2}{|c|}{$p<0.001$} & \multicolumn{2}{|c|}{$\mathrm{P}=0.968$} \\
\hline Overall & $24,275(97 \%)$ & 799 (3\%) & $10,130(79 \%)$ & $2,753(21 \%)$ & $10,165(58 \%)$ & $7,394(42 \%)$ \\
\hline No & $13,362(98 \%)$ & $337(2 \%)$ & $3,827(92 \%)$ & $319(8 \%)$ & $4,092(88 \%)$ & $559(12 \%)$ \\
\hline Yes & $10,913(96 \%)$ & $462(4 \%)$ & $6,303(72 \%)$ & $2,434(28 \%)$ & $6,073(47 \%)$ & $6,835(53 \%)$ \\
\hline $\begin{array}{l}\text { Would buy vegetable from a vendor who } \\
\text { has HIV }\end{array}$ & \multicolumn{2}{|c|}{$p<0.001$} & \multicolumn{2}{|c|}{$\mathrm{p}<0.001$} & \multicolumn{2}{|c|}{$P<0.001$} \\
\hline Overall & $22,014(96 \%)$ & $799(4 \%)$ & $8,987(77 \%)$ & $2,753(23 \%)$ & $9,708(57 \%)$ & $7,394(43 \%)$ \\
\hline No & $15,218(97 \%)$ & $427(3 \%)$ & $6,023(81 \%)$ & $1,435(19 \%)$ & $2,496(73 \%)$ & $922(27 \%)$ \\
\hline Yes & 6, 796 (95\%) & 372 (5\%) & 2, 964 (69\%) & I, $318(3 \mid \%)$ & $7,2 \mid 2$ (53\%) & $6,472(47 \%)$ \\
\hline
\end{tabular}

Note: $P$ value represents chi2 test.

$\mathrm{N}=$ Number of respondents 
Table 2: Multivariable regression models: Estimation of the likelihood of HIV testing based on sociodemographic characteristics, HIV related knowledge and Stigma

\begin{tabular}{|c|c|c|c|}
\hline Country \& survey year & Philippines (2017) & Myanmar (2015-16) & Cambodia (2014) \\
\hline Original number of observations & 25,074 & 12,885 & 17,578 \\
\hline \multirow[t]{2}{*}{ Observations used in this analysis } & 22,813 & II, 728 & 17,090 \\
\hline & $\chi^{2}(d f=15)=633.92$ & $\chi^{2}(\mathrm{df}=16)=2,115.54$ & $\chi^{2}(d f=16)=5,764.67$ \\
\hline Prob>chi2 & 0.001 & 0.001 & 0.001 \\
\hline Pseudo R2- & 0.091 & 0.166 & 0.247 \\
\hline Log-likelihood & $-3|45.9| \mid$ & -5330.894 & -8806.411 \\
\hline Variables & & OR (95\% Confidence Inter & \\
\hline \multicolumn{4}{|l|}{ Age } \\
\hline $15-19$ & Reference & Reference & Reference \\
\hline $20-24$ & $2.82(1.58,5.04) * * *$ & $3.34(2.30,4.85) * * *$ & $2.31(1.88,2.84) * * * *$ \\
\hline $25-29$ & $3.94(2.12,7.33) * * *$ & $4.76(3.37,6.73) * * *$ & $2.44(1.97,3.03) * * *$ \\
\hline $30-34$ & $3.73(1.89,7.39) * * *$ & $4.30(3.02,6.14) * * * *$ & $\mathrm{I} .43(\mathrm{I} .14, \mathrm{I} .8 \mathrm{I}) * *$ \\
\hline $35-39$ & $2.99(1.47,6.08) * *$ & $3.96(2.70,5.8 I)$ **** & $0.72(0.57,0.91) * *$ \\
\hline $40-44$ & $2.96(1.46,6.00) * *$ & $2.40(1.65,3.50) * * *$ & $0.38(0.30,0.49) * * *$ \\
\hline $45-49$ & I. $18(0.57,2.45)$ & $1.27(0.86,1.88)$ & $0.23(0.18,0.30) * * * *$ \\
\hline \multicolumn{4}{|l|}{ Place of residence } \\
\hline Urban & Reference & Reference & Reference \\
\hline Rural & $0.42(0.29-0.61) * * *$ & $0.67(0.55,0.8 \mathrm{I}) * *$ & $0.52(0.45,0.61) * * *$ \\
\hline \multicolumn{4}{|l|}{ Education } \\
\hline No education/Primary education & Reference & Reference & Reference \\
\hline Secondary & I.44 $(0.85,2.44)$ & $1.43(1.24,1.65) * * *$ & $1.39(1.25-1.55) * * * *$ \\
\hline Higher & $2.66(I .60,4.4 I) * * *$ & $2.67(2.08,3.43)$ **** & $1.68(1.35,2.09) * * *$ \\
\hline \multicolumn{4}{|l|}{ Wealth } \\
\hline Poor & Reference & Reference & Reference \\
\hline Middle & $1.43(1.02,2.00) *$ & $1.20(1.00,1.43) *$ & $1.21(1.05,1.39) * *$ \\
\hline Rich & $1.85(1.24,2.74) * *$ & $1.75(1.44,2.14) * * *$ & $1.59(1.37,1.85) * * *$ \\
\hline \multicolumn{4}{|l|}{ Marital status } \\
\hline Never in union & Reference & Reference & Reference \\
\hline Ever in union & $1.94(1.27,2.97) * *$ & $5.85(4.76,7.20) * * *$ & $19.43(15.95,23.67) * * *$ \\
\hline \multicolumn{4}{|l|}{ Current employment status } \\
\hline No employment & Reference & Reference & Reference \\
\hline Currently employed & $\mathrm{I} .35(\mathrm{I} .09, \mathrm{I} .67)$ ** & $0.75(0.66-0.85) * * *$ & $0.83(0.74-0.92) * * *$ \\
\hline \multicolumn{4}{|c|}{ Would buy vegetables from a vendor who has HIV } \\
\hline No & Reference & Reference & Reference \\
\hline Yes & $1.26(0.99,1,59)$ & $1.37(1.22,1.53) * * *$ & $1.65(1.45-1.87) * * *$ \\
\hline \multicolumn{4}{|l|}{ HIV knowledge } \\
\hline Knowledge score & $1.11(1.04-1.18) * * *$ & $1.18(1.13-1.22) * * *$ & $1.11(1.08-1.15) * * *$ \\
\hline $\mathrm{I}$ & $0.65(0.30,1.42)$ & $0.91(0.63,1.32)$ & I.II $(0.80,1.54)$ \\
\hline 2 & $0.93(0.40,2.19)$ & I.3I (0.93. I.85) & $\mathrm{I} .15(0.85, \mathrm{I} .56)$ \\
\hline 3 & $1.44(0.64,3.27)$ & $1.52(1.06,2.16) *$ & $1.46(1.09,1.96) *$ \\
\hline
\end{tabular}


Table 2: (Continued)

\begin{tabular}{lccc}
\hline Country \& survey year & Philippines (20I7) & Myanmar (20I 5- I6) & Cambodia (20I4) \\
\hline 4 & $1.75(0.83,3.72)$ & $1.74(1.23,2.47) * *$ & $1.54(1.15,2.05)$ ** \\
\hline 5 & $1.67(0.81,3.54)$ & $1.45(1.03,2.05) *$ & $1.28(0.94,1.75)$ \\
\hline 6 & $1.50(0.65,3.46)$ & $1.35(0.91,2.00)$ & $1.28(0.77,2.12)$ \\
\hline cons & $0.00(0.00-0.01)^{* * *}$ & $0.01(0.01-0.02) * * *$ & $0.04(.04-0.06) * * *$ \\
\hline
\end{tabular}

Note: cons estimates baseline odds. $P<0.05 *, P<0.0$ I **, $P<0.001 * * *$

was observed in the Philippines (aOR $=1.85,95 \%$ Cl:1.24 -2.74).

\section{I.5. Marital status}

$75 \%$ of respondents in Cambodia, $67 \%$ of respondents in Myanmar, and 64\% from the Philippines were ever-married. These women were more likely to get tested for HIV than those never married, and the highest odds ratio was observed in Cambodia $(\mathrm{aOR}=19.43,95 \% \mathrm{Cl}: 15.95-23.67)$.

\section{I.6. Employment}

71 $\%, 67 \%$, and $46 \%$ of respondents from Cambodia, Myanmar, and the Philippines, respectively, were employed. Employed women were significantly more likely to get tested for HIV in the Philippines $(\mathrm{aOR}=1.35,95 \% \mathrm{Cl}$ : I.09-1.67) than those who were unemployed. On the contrary, employed women were significantly less likely to get tested for HIV than unemployed women in Myanmar and Cambodia (Myanmar: $\mathrm{aOR}=0.75,95 \% \mathrm{Cl}: 0.66-0.85$ and Cambodia: $\mathrm{aOR}=0.83$, 95\% Cl: 0.74-0.92).

\subsection{Main Variable (Dependent or Outcome) Results}

Our primary outcome variable, having ever been tested for HIV, showed a noteworthy difference in testing rates among women: $5 \%$ in the Philippines, $19 \%$ in Myanmar, and $42 \%$ in Cambodia.

\subsection{Other Variable(s) Results}

\subsection{HIV knowledge score}

Nearly all (95\%) respondents received at least one out of six possible points in responding to HIV knowledge questions in all three countries. Only $4 \%$ in the Philippines, $6 \%$ in Myanmar, and 3\% in Cambodia received zero out of six.
The results of independent samples t-tests are described in Table 3. In the Philippines, there were significant differences in the knowledge score between women who got tested for HIV [Mean $(M)=3.87$, Standard Deviation $(S D)=1.28]$ and those who did not $(M=3.60, S D=I .54)$. In Myanmar, there were statistically significant differences in the knowledge score between women who got tested for HIV $(M=3.60, S D=1.39)$ and those who did not $(M=3.52, S D=1.66)$. Similarly, in Cambodia, there were statistically significant differences in the knowledge score between women who have been tested for HIV $(M=3.23, S D=I .13)$ and those who have not $(M=3.15, S D=1.30)$

In Myanmar (74\%) and Cambodia (54\%), the logistic regression result showed a greater likelihood of getting tested for HIV among the women who had some HIV knowledge (especially among those who correctly responded to three or four knowledge questions) than those who did not. Higher odds ratios were seen in Myanmar (aOR=I.74, 95\% Cl:1.232.47) and Cambodia (aOR=I.54, 95\% Cl: I. I5-2.05). These results were not statistically significant in the Philippines, where testing rates were much lower.

\subsubsection{Stigmatizing attitude towards PLWHIV}

Among the respondents, $68 \%$ from the Philippines, $65 \%$ from Myanmar, and 21\% from Cambodia displayed some evidence of stigmatizing attitudes, saying they would not buy vegetables from a vendor who was HIV positive. Women who reported less stigma were significantly more likely to have been tested for HIV in Cambodia and Myanmar (Cambodia: $\mathrm{aOR}=\mathrm{I} .66,95 \% \mathrm{Cl}: \mathrm{I} .45-\mathrm{I} .87$, Myanmar: $\mathrm{aOR}=\mathrm{I} .37$, 95\% Cl: I.22-I.53). In the Philippines, women who reported less stigma were more likely to get tested for HIV, but it was not significant at the $\mathrm{p}<.05$ level $(\mathrm{aOR}=1.26,95 \% \mathrm{Cl}: 0.99-1.59)$. 
Table 3: t-test results comparing HIV testing status based on their HIV Knowledge in three countries

\begin{tabular}{|c|c|c|c|c|c|}
\hline & Mean (SD) & $\begin{array}{l}\text { Mean difference } \\
\text { between groups }\end{array}$ & t-statistic (df) & $95 \% \mathrm{Cl}$ & \\
\hline Philippines & & -0.28 & $-5.94(884)$ & $3.59,3.63$ & $<.001$ \\
\hline No & $3.60(1.54)$ & & & & \\
\hline Yes & $3.87(1.28)$ & & & & \\
\hline Myanmar & & -0.08 & $-2.51(5339)$ & $-0.18,-0.01$ & $<0.05$ \\
\hline No & $3.52(1.66)$ & & & & \\
\hline Yes & $3.60(1.39)$ & & & & \\
\hline Cambodia & & -0.07 & $-3.83(16782)$ & $-0.12,-0.02$ & $<0.001$ \\
\hline No & $3.15(1.30)$ & & & & \\
\hline Yes & $3.23(1.13)$ & & & & \\
\hline
\end{tabular}

Note: $\mathrm{SD}=$ Standard Deviation, $\mathrm{t}=\mathrm{t}$-statistics, $\mathrm{df}=$ degree of freedom

\section{Discussion}

\section{I. Discussion}

A relatively small percentage of Filipino women (5\%) were tested for HIV, compared to the other two countries. In the Philippines, Philhealth, a National Health Insurance, covered outpatient HIV/AIDS treatment costs. ${ }^{24}$ The average initial cost per ART patient was the Philippines peso P7,920 (\$160 US). ${ }^{25}$ Also, the HIV epidemic shifted from men-to-women to men-to-men transmission since 2007, which perhaps explained the focus of HIV testing was turned to men. ${ }^{10}$ Nevertheless, one of the strategies to reach more women could be including HIV testing cost coverage in the Philhealth and the expansion of community-based HIV testing and HIV self-testing.

The estimated percentage of MTCT of HIV in Myanmar was about $16.9 \%$ (in 2019). $88 \%$ of pregnant women received pre-test HIV counseling, and $95 \%$ of those got tested for HIV in 2019.9 The high percentage could be for many reasons. In Myanmar, between 20I I2015, Provider Initiated HIV Counseling and Testing (PICT) was integrated with the nationwide antenatal care (ANC) services. ${ }^{26}$ HIV testing and ART for all PLWHIV were free as the Global Fund (the largest donors, providing about $45-50 \%$ of total funding), the Myanmar government, and the multi-countries donors covered the cost despite no health insurance. ${ }^{9}$ The estimated average ART unit cost per ART patient was $\$ 190$ US in 2021.9 Our analysis showed that HIV testing among women of reproductive age 15-
49 in Myanmar was only 19\% in 2015. Although the HIV testing among pregnant women was high at $88 \%$ in 2019, this highlighted the gap that affordable and accessible services are needed for women who are not currently pregnant (because the PICT was only for pregnant women coming for services). ${ }^{26}$

Compared to the other two countries, Cambodia had the highest percentage of women tested for HIV (42\%). HIV services for both testing and treatment were free, with a significant portion of treatment cost supported by the Royal Government of Cambodia and external donors (the U.S. Government, the Global Fund, and other non-governmental organizations). ${ }^{27}$ The average initial treatment cost of ART patients per year was about $\$ 250$ US. ${ }^{27}$

We found that the testing rate among the women in our sample was very low compared to the UNAIDS data. Our data were predicted from the household survey from 2014 to 2017 , whereas the UNAIDS current prevalence data are calculated estimates based on the respective country's program data of $2020 .^{11,18-20}$ The timing and the source of data collection were different.

Having some HIV knowledge was a strong predictor for receiving an HIV test in Myanmar and Cambodia. The result was consistent with a previous study, which found that knowledge led to an increased HIV testing uptake. ${ }^{15}$ Regarding stigma, our finding demonstrated that women who did not show stigma toward those with HIV were about 
I.26 to I.65 times more likely to have received an HIV test than those who had some stigma, especially in Cambodia and Myanmar. These findings were consistent with the findings from the previous studies conducted in four countries in Central Asia and Mozambique that the person having an anticipated stigma towards PLWHIV was significantly associated with lower uptake of HIV testing. ${ }^{16,28}$

Consistent with previous studies,sociodemographic characteristics, including marital status, education, socioeconomic status, and employment, were strong predictors of HIV testing. ${ }^{15,28,29}$ In our analysis, marital status was one of the strongest predictors for HIV testing, especially in Cambodia. The results demonstrated that married people were more likely to get tested for HIV. The law in each country regarding the disclosure of communicable diseases may have some influence on it. For example, the law in Cambodia prohibits the acts of persons with HIV who intend to transmit HIV to other people. ${ }^{30}$ In the Philippines, under the family code, hiding one's HIV status can be regarded as an annulled marriage. ${ }^{30} \mathrm{Also}$, the Philippine HIV and AIDS Policy Act 2018 (section 47) strongly encourage PLWHIV to disclose their HIV status to a spouse, sexual partner, or other people prior to engaging in penetrative sex or any potential exposure to HIV. ${ }^{30}$ Although Myanmar does not have a similar HIV law, Sections 269 and 270 of Chapter XIV under Myanmar Penal Code states the Offences on Affecting the Public Health, Safety, Convenience, Decency, and Morals. ${ }^{30}$ However, many people did not seem aware of it. Although the Myanmar National AIDS Program (NAP) recognized the importance of disclosure and protecting individual rights, there were no known reported cases.

The other two impactful predictors for getting tested for HIV were education and wealth status, which were also consistent with the findings from a previous study. ${ }^{29}$ The women with higher education were more likely to get tested for HIV than those with low or no education. Similarly, the rich were more likely to get tested for HIV than the poor for wealth status. In the Philippines, wealthier women were more likely to get tested for HIV, although the result was not significant. In a previous study conducted in three African countries and one Asian country, employment has been significantly associated with increased HIV testing. ${ }^{29}$ However, in Myanmar and Cambodia, our results demonstrated that the employed women were less likely to get tested for HIV than those who responded unemployed. One of the possibilities in the Filipino women in employment could be that they could afford to cover the cost of HIV testing and the cost associated with it (e.g., transportation to reach the HIV testing facility). For Myanmar and Cambodia, the HIV testing center, which provided free either be government testing center or NGO testing center, was opened Monday through Friday and therefore, women in any type of employment may have difficulties to have HIV test during their working hours. Further studies might need to explore the association between employment and HIV testing uptake among women.

Age and residence (urban/rural) were also strong predictors of HIV testing among women. Findings from this analysis agreed with the results from previous studies. ${ }^{14,16}$ Our findings suggested that the younger respondents were less likely to get an HIV test than older women. This finding was consistent with the findings from the study done in the Central Asia countries, in which the younger women were less likely to get an HIV test. ${ }^{16}$ However, the finding conflicts with a study done in four countries (South Africa, Zimbabwe, Tanzania, Thailand) that found that younger respondents were more likely to get tested..$^{29}$ This could be because our study focused on women of different age groups ranging from 15-49, whereas the previous study only compared two age groups ( 15 to 24 vs. 25 to 32 ). ${ }^{29}$ Additionally, our data did not permit us to analyze behavioral risk factors. In contrast, the previous study compared two age groups with multiple sex partners vs. singlesex partners related to HIV testing. Nevertheless, the fact that the younger respondents were less likely to get tested for HIV highlighted a need for early HIV testing intervention for women younger than age 20 to know their HIV status and take appropriate care and treatment options. In our finding, the odds of having been tested for HIV 
among rural women were less than those who live in the urban area. ${ }^{14}$

Our analysis highlighted that specific strategies are needed to get tested for HIV early and future research focusing on young women could be beneficial. In countries with successful EMTCT, governments' commitment to free HIV testing and treatment, service integration for HIV and maternal health, and engagement with the different stakeholders were strong. ${ }^{8}$ For example, Thailand provided free antenatal HIV testing, and Maldives provided a range of HIV prevention and control services at all health facilities. ${ }^{8}$ Similarly, the Sri Lanka government collaborate with different partners to ensure that women have access to contraceptives and qualified birth attendants. ${ }^{8}$

\subsection{Strengths and Limitations of the Study}

This study used a large and nationally representative data set, however, there were some limitations. Low rates of testing in the Philippines presented challenges for significance testing. Also, the concept of stigma is complex, and firm conclusions related to stigma were challenging since only one question that was asked consistently throughout all three countries was used.

\section{Conclusion and Global Health Implications}

Overall, this study helps us understand the influence of social determinants impacting HIV testing among women, especially younger women aged 15-19, who may need HIV testing can have testing promoted to them. Given that these countries are resourcelimited and stigma played a considerable role in deterring HIV testing, programs and policies should aim to reach younger women through different testing approaches integrated with stigma reduction strategies to have early treatment.

\section{Compliance with Ethical Standards}

Conflicts of Interest: The authors declare no competing interests. Financial Disclosure: Nothing to declare. Funding/Support: There was no funding for this study Ethics Approval: The protocol for DHS surveys was reviewed and approved by the Inner City Fund (ICF) Institutional Review Board (IRB) for all three countries and respective country's Ministry of Health or Executive and Technical committee (for the Philippines and Cambodia) or Ethics Review Committee (for Myanmar). Informed consent was obtained from each interviewee before the survey. Acknowledgments: The authors thank the DHS program for providing free access to DHS data sets of three countries (the Philippines, Myanmar, and Cambodia). Disclaimer: None.

\section{Key Messages}

Availability of different testing options could facilitate reaching women with low levels of education, different employment statuses, and less familiarity with HIV.

Reaching the elimination of Mother-to-Child Transmission (EMTCT) and global goals of achieving $90 \%$ targets will be a challenge with existing and currently available testing strategies. Focus on stigma reduction could also improve HIV testing uptake for women.

\section{References}

I. UNAIDS report. Global data on HIV epidemiology and response. Accessed September 30, 2021. https://aidsinfo. unaids.org

2. World Health Organization. Global Guidance on Criteria and Process for Validation: Elimination of Mother to Child Transmission of HIV and Syphilis. $2^{\text {nd }}$ edition; 2017: 17.

3. UNAIDS report. 90-90-90: An ambitious treatment target to help end the AIDS epidemic. Accessed October I, 202I. https://www.unaids.org/en/resources/909090

4. Cohen MS, Chen YQ, McCauley M, et al; the HPTN 052 Study Team. Prevention of HIV-I infection with early antiretroviral therapy. N Engl J Med. 20I I;365(6):493-505. doi:I0.1056/NEJMoa I I 05243

5. Centers for Disease Control and Prevention. HIV Testing. Accessed August 9, 2020. https://www.cdc.gov/hiv/testing/ index.html.

6. Hollingsworth TD, Anderson RM, Fraser C. HIV-I Transmission by stage of infection. J Infect Dis. 2008; | 98(5):687-693. doi: I0.1086/59050 |

7. HIV and pregnant women, infants, and children. Centers for Disease Control and Prevention. Updated September 22, 2021. Accessed September 25, 202I. https://www.cdc.gov/ hiv/group/gender/pregnantwomen/index.html

8. World Health Organization. WHO Validation For The Elimination of Mother-To-Child Transmission of HIV and/or Syphilis. Accessed October 3, 2021. https://www.who.int/ reproductivehealth/congenital-syphilis/WHO-validationEMTCT/en

9. Myanmar Ministry of Health and Sports. National Strategic 
Plan on HIVIAIDS, Myanmar. 202 I-2025. 2020.

10. Department of Health Epidemiology Bureau Philippines. HIVIAIDS and ART Registry of the Philippines. Accessed October 3, 202I. https://drive.google.com/drive/ folders/IGiUUoZoi87A_WVX-Zt_3p6exZpo3S59K

II. UNAIDS report. National HIV estimates file. Accessed October 19, 2021. https://www.unaids.org/en/dataanalysis/ datatools/spectrum-epp

12. Eng CW, Tuot S, Chann N, Chhoun P, Mun P,Yi S. Recent HIV testing and associated factors among people who use drugs in Cambodia: a national crosssectional study. BMJ Open. 202 I; I I (e045282). doi: I 0. I | 36/bmjopen-2020-045282

I3. Pepito VCF, Newton S. Correction: Determinants of HIV testing among Filipino women: Results from the 2013 Philippine National Demographic and Health Survey. PLoS One. 2020;15(5):e0232620. doi:10.137|/journal. pone. 0246013

14. Hone S, Li L, Lee S, Comulada WS, Detels R. Progress and challenges of implementing decentralized HIV testing for prevention of mother-to-child transmission of HIV Myanmar. Int J MCH Aids. 2019;8(I):44-53. doi:10.2I I06/ ijma.276

15. Haile BJ, Chambers JW, Garrison JL. Correlates of HIV Knowledge and Testing: results of a 2003 South African survey. J of Black Studies. 2007;38(2):194-208. doi: I0.1 I77/002 I 934705285595

16. Smolak A, El-Bassel N. Multilevel stigma as a barrier to HIV testing in Central Asia: a context quantified. AIDS Behav. 20|3; I 7(8):2742-55. doi: I0.1007/s I046 I-0 I 3-057|-4

17. The Joint United Nations Programme for HIV/AIDS. Miles to go: The Response to HIV in Asia and the Pacific. UNAIDS; 2018. Accessed October 3, 2021. https://www.unaids.org/ sites/default/files/media_asset/miles-to-go_asia-and-thepacific_en.pdf

18. Philippine Statistics Authority (PSA), ICF. Philippines National Demographic and Health Survey 20I 7. PSA and ICF; 2018.

19. National Institute of Statistics Directorate General for Health, ICF. Cambodia Demographic and Health Survey 2015. National Institute of Statistics, Directorate General for Health, and ICF International; 2015.

20. Ministry of Health and Sports, ICF. Myanmar Demographic and Health Survey 2015-16. Ministry of Health and Sports and ICF; 2017.

21. Demographic and Health Surveys. Methodology. The DHS Program. Accessed July 13, 2020. https://dhsprogram.com/ methodology
22. Demographic Health Surveys. Wealth Index. The DHS Program. Accessed September 25, 2021. https:// dhsprogram.com/topics/wealth-index

23. StataCorp. Stata Statistical Software: Release I6. College Station, TX: StataCorp LP; 2019.

24. Philhealth. Philhealth Stats and Charts. Accessed September 28, 202I. https://www.philhealth.gov.ph/about_us/ statsncharts

25. HIV treatment in the Philippines. HIVtestkit.ph. Accessed August 13, 2020. https://hivtestkit.ph/hiv-treatment-in-thephilippines

26. Oo HN, Hone S, Fujita M, et al. Evolution of the health sector response to HIV in Myanmar: progress, challenges and the way forward.J Virus Erad. 2016;2(Suppl 4):20-26.

27. Thin K, Prum V, Johns B. The cost of HIV services at health facilities in Cambodia PLoS One. 2019;|4(5):e0216774. doi:I0.137|/journal.pone.0216774

28. Ha JH, Lith LMV, Mallalieu EC, et al. Gendered relationship between HIV stigma and HIV testing among men and women in Mozambique: a cross-sectional study to inform a stigma reduction and male-targeted HIV testing intervention. BMJ Open. 2019; 9:e029748. doi:10.1136/ bmjopen-2019-029748

29. Salazar-Austin N, Kulich M, Chingono A, et al; NIMH Project Accept (HPTN 043) Study Team. Age-related differences in socio-demographic and behavioral determinants of HIV testing and counseling in HPTN 043/NIMH Project. AIDS Behav. 20I7;22(2):569-579. doi:I0.1007/s I 046I-0I7-I807-5

30. Global HIV criminalization database: laws and analyses. HIV Justice Networks. Accessed March 20, 2021. https://www. hivjustice.net/global-hiv-criminalisation-database/laws/

PUBLISH IN THE INTERNATIONAL JOURNAL of Maternal and Child Health and AIDS

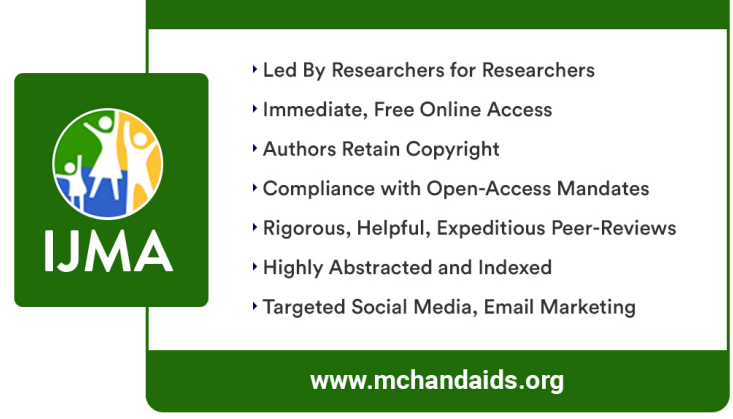

